
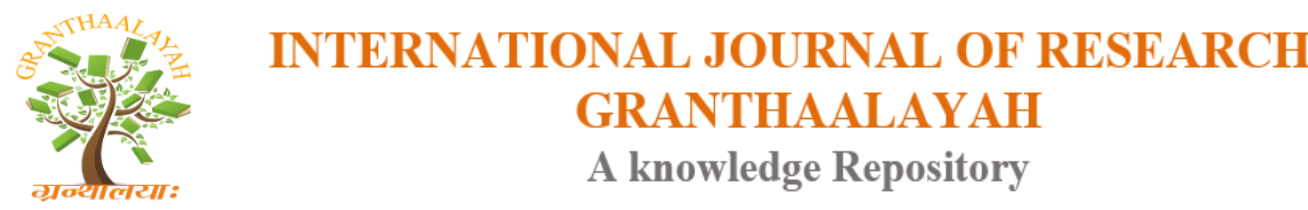

Management

\title{
STOCHASTIC FRONTIER APPROACH OF VALUE ADDED MEASURES OF SUGAR PRODUCTION IN BANGLADESH: AN EMPIRICAL ANALYSIS
}

\author{
Dr. Md. Abdus Sabur ${ }^{1}$, Dr. Md. Abu Sina ${ }^{2}$ \\ ${ }^{1}$ Associate Professor, Department of Accounting \& Information Systems, Islamic University \\ Kushtia, Bangladesh \\ ${ }^{2}$ Professor, Department of Accounting \& Information Systems, Islamic University, Kushtia, \\ Bangladesh
}

\begin{abstract}
An attempt has been taken to explore the causes of inefficiency of management of sugar industry in Bangladesh by applying Stochastic Frontier Approach (SFA) that contains three steps of estimation. According to value of output measurement by SFA, $\sigma$ parameter was found with positive values indicating potential production deferred from actual production. The return to scale of the sample was estimated 1.84 implied increasing returns to scale. The parameter $\left(\beta_{0}\right)$ of OLS for the sample was found less than that of MLE for the cause of below position of potential output. $\lambda$ (Lambda) was the ratio of variance of industry specific production behaviors $\sigma^{2}(\mathrm{u})$ to the variance of statistical noise $\sigma^{2}(\mathrm{v})$. Here that ratio was found 1.69 and 1.11 for the half-normal and truncated normal distribution which indicated that there were impacts due to inefficiency of the management dominated by random disturbances of the sugar industry in Bangladesh. The value of $\gamma$ was estimated 74 percent and 55 percent for half normal and truncated normal indicating 74 percent and 55 percent output in sugar production were due to inefficiency of the management. The parameter $(\eta)$ was found negative for both the methods which indicated that the technical efficiency was decreasing over the time. The mean technical efficiency of sample was 54.45 percent and 35.45 percent for the half normal and truncated normal distribution. This further indicated that the management could increase the production level by 45.55 percent and 64.55 percent respectively using same level of inputs. The suggestion and recommendation has been provided to improve managerial skills, increase skilled manpower, introduce higher sucrose content cane, modernization of machineries and reduction of overhead cost.
\end{abstract}

Keywords: Stochastic Frontier Approach; Sensitivity Analysis; Half Normal and Truncated Normal.

Cite This Article: Dr. Md. Abdus Sabur, and Dr. Md. Abu Sina. (2018). "STOCHASTIC FRONTIER APPROACH OF VALUE ADDED MEASURES OF SUGAR PRODUCTION IN BANGLADESH: AN EMPIRICAL ANALYSIS." International Journal of Research - Granthaalayah, 6(5), 289-299. https://doi.org/10.29121/granthaalayah.v6.i5.2018.1451. 


\section{Introduction}

Low productivity of agriculture sector coupled with unemployment of a large segment of the population is an acute problem of the country. While agriculture sector provides only a limited employment opportunity, without industrial development the unemployment problem cannot be removed. In other case without full employment industrial development is impossible. So, in our economic planning every government has given emphasis to industrial development. But there are many reasons we cannot advance effectively. In our GDP industrial contribution only 29.88 percent while the growth rate of the sector stands at 6 percent (Ministry of Finance, 2010). The picture appears to be quite disconcerting. As an independent nation, Bangladesh has already passed the 40 years of its existence, which is considered to be reasonable long period to achieve a breakthrough by now in order to line up with other emerging developing countries.

Though Bangladesh economy is mainly based on agriculture, simply agricultural development cannot suffice for raising economic prosperity of the people. For the sake of proper economic development, to meet unemployment problem, there is no alternative to rapidly industrialize, which should base on our agriculture. The balance development between agriculture and industry, and the structural shift from agriculture to industry consider welcome proposition in the contest of Bangladesh.

A sugar factory crushes sugarcane for approximately six months of a year, ranging from September until May. The technology is fairly straightforward: cane is crushed to yield juice in the mill house, which is evaporated in the boiler house and crystallized to yield sugar. Sugarcane procurement constitutes the bulk (60\%-70\%) of the cost of a factory. The harvested cane needs to be crushed within a few hours to avoid loss of sucrose content, necessitating close coordination of harvesting and cane supply with cane crushing operation. According to the recommendation of FAO and Bangladesh Nutritious Council, 9.00kg sugar is required per head annually for Bangladeshi citizen. For 14 crore people of Bangladesh, the total demand of sugar per year is estimated about 14.00 lakh metric tons of sugar. But the production capacity of 15 sugar mills is only 2.10 lakh MT of sugar. It is clear that the production capacity of sugar of 15 sugar Mills and imported sugar from foreign countries have been full filling the demand of sugar of our country. The spare parts of most of the sugar mills are very old, so the production capacity of the mills decreased to a great extent. Out of the 15 sugar mills 11 sugar mills have already lost their economic life (20 year). However, proper repairs and maintenance are helping to running the sugar mills somehow (BSFIC, 2009)

The sugar industry is the 2nd agro-based and labor intensive industry next to Jute industry in terms involvement of farmers and employment of labors. The industry has an important role to play in economic development of our Bangladesh. Many of the research studies highlighted that the inherent operational inefficiencies are the results of low profit, high cost of production, financial crisis and long-term solvency of the industry. If the input-output relationship is developed then strength, weakness, threats and opportunities of the sugar sector would be viable and BSFIC would be able to face the chronic situation of net losses. The survival of the sugar mills depends mainly on full capacity utilization and available supply of quality sugarcane. Based on extensive reviewed of related research study the following factors affect the input-output measurement of the sugar sector. Lack of proper facilities, renovation, modernization and expansion of existing sugar mills; low technical efficiency, productivity, economic efficiency, operating efficiency, value added etc. are also remarkable. Underutilization of production capacity of sugar mills, diversion of sugarcane 
for gur production causes shortage of supply. Strained relationship between mill management and sugarcane growers; poor quality and decreasing yield position of sugarcane; absence of rational price of sugarcane; dismal condition of roads and other means of communications that provide misuse of sugarcane are the major problems of sustainable development of sugar industry in Bangladesh.

\section{Related Literature Review}

To make a clear idea of the study the following reviews of the related literature have been furnished below:

The paper has examined the efficiency of the large scale manufacturing sector of Pakistan using the stochastic production frontier approach. The results showed that there had been some improvement in the efficiency of the large scale manufacturing sector, though the magnitude of improvement remains small. The results were mixed at the disaggregated level, whereas a majority of industrial groups had gained in terms of technical efficiency, some industries had shown deterioration in their efficiency levels including, for example, transport equipment, glass and glass products, other non-metallic mineral products, and other manufacturing. There would be several factors that might be caused a decline in the technical efficiency of such firms, not least the trade policy environment that might be shielded such industries from external competition (Mahmud, Gani \& Uddin 2006). It was found out by the authors that a firm's ownership structure and its characteristics are important for its technical efficiency. The determinants of firm level technical efficiency was identified by stochastic frontier approach as technical efficiency was higher in foreign ownership firms compared to employee and state ownership; firm size and higher labor quality caused to enhance efficiency, while insufficient budget affected efficiency harmfully; Estonian firms operate under constants returns to scale and a remarkable numbers of firms were found to operate increasing technical efficiency over time (Sinani, Jones, \& Mygind, 2005). The authors identified that the mean technical efficiency of large, medium, small, marginal and samples rice production farms were found to be $0.88,0.92,0.94,0.75$ and 0.88 respectively. The selected farmers could increase on an average, 12 percent output with the existing inputs and production technology. The important elements to increase production were recognized as fertilizer, manure, irrigation cost, insecticide cost, area under production and experience of farmers. They also found that technical inefficiency effect, age, education and family size had positive impact on efficiency effect, whereas land under household had negative impact on efficiency effect (Rahman, Mia, \& Bhuiyan, 2012). In this research work, the stochastic frontier method was applied to build a model of performance measurement for the firms listed on Indonesia Stock Exchange (IDX). It was identified that the technical inefficiency of the manufacturing sector depended on firm's age, size, market share, manufacturing classifications and time period. The findings also estimated the average technical efficiency 0.7194 of the selected firms which was below the efficient frontier (Prabowo \& Cabanda, 2011). By this study, an attempt was taken to find out the level of technical efficiency of pharmaceutical manufacturing firms in Ghana and examined the factors that those were responsible to change efficiency level. The findings show that technical efficiency level among firms range between about $34 \%$ and $62 \%$ with the mean technical efficiency level of $50 \%$. In addition, the results show that percentage of professionals employed by firms, the ages of firms' plants and the number of maintenance exercises by firms significantly determined their technical efficiency level. Furthermore, capital and skilled labor had greater positive impacts on output 
levels of capsules and tablets produced (Asante \& Sekyi, 2016). In this paper, a stochastic frontier approach was applied to compute an explicit performance benchmark that compares a firm's actual Tobin's Q to the Q* of a hypothetical fully-efficient firm having the same inputs and characteristics as the original firm. The $\mathrm{Q}$ of the average sample firm is around $16 \%$ below its $\mathrm{Q} *$, equivalent to a $\$ 1,432$ million reduction in its potential market value. The extent of inefficiency is related to the inadequate provision of internal incentives. The effectiveness of the incentives we consider depends on company size and, to a lesser degree, industry (Habib \& Ljungqvist, 2003).

\section{Some Important Concepts of the Study}

An attempt has been taken for a brief discussion about conceptual and theoretical framework as follows:

\subsection{Concept of Efficiency}

\subsubsection{Technical Efficiency}

It deals with the usage of labor, capital, and machinery as inputs to produce outputs relative to best practice in a given sample of decision making units (DMUs). In other words, given same technology for all the DMUs no wastage of inputs is considered in producing the given quantity of output. An organization operating at best practice in comparison to all others in the sample is said to be totally technically efficient. The organizations are benchmarked against the best organization and their technical efficiency is expressed as a percentage of best practice. Managerial practices and the scale of operations affect technical efficiency. This is due to scale of operation and is based on engineering relationships but not on prices and costs ( Bhat, Verma \&Reuben, 2001).

\subsubsection{Allocative Efficiency}

It deals with the minimization of cost of production with proper choice of inputs for a given level of output and set of input prices, assuming that the organization being examined is already fully technically efficient. Allocative efficiency is expressed as a percentage score, with a score of 100 percent indicating that the organization is using its inputs in the proportions which would minimize costs. An organization that is operating at best practice in engineering terms could still be allocatively inefficient because it is not using inputs in the proportions, which minimize its costs, given relative input prices (Bhat et al., 2001).

\subsubsection{Cost Efficiency}

It deals with combination of technical and allocative efficiency. An organization will only be cost efficient if it is both technically and allocatively efficient. Cost efficiency is calculated as the product of the technical and allocative efficiency scores (expressed as a percentage), so an organization can only achieve a 100 per cent score in cost efficiency if it has achieved 100 percent in both technical and allocative efficiency (Bhat et al., 2001). 


\subsubsection{Value of Production}

Productivity is measured in terms of output. Output is most commonly measured in terms of value but some cases physical units are also used. Production in terms of value can be measured either as the real value of turnover or the real value added. However, turnover does not provide a precise measure of productivity as it incorporates a fair amount of double counting due to value added by bought in inputs. Therefore, production is measured as the real value added by the industry. Value added is defined as sales less the cost of raw materials, services and components to produce them. When output is defined as value added, the factor inputs are labor and capital (Muellabuer, 1991).

\section{The Stochastic Frontier Production Function}

The empirical model used in the present study is as below:

$\ln \mathrm{y}_{\mathrm{j}}=\ln \beta_{o}+\sum_{i=1}^{n} \beta_{i} \ln X_{i j}+\mathrm{v}_{\mathrm{i}}-\mathrm{u}_{\mathrm{i}}$ where $\mathrm{i}=$ Number of variables used, $\mathrm{j}=$ Number of observations, $\mathrm{y}=$ The total value of output, $\mathrm{v}_{\mathrm{i}} \mathrm{S}$ are assumed to be independent and identically distributed as normal random variables with mean zero and variance, $\sigma_{v}{ }^{2}$, independent of $u_{i} s$.

The stochastic frontier production function was used to assess the efficiency of selected sugar Mills under study period. The stochastic frontier production function is defined by the equation:

$\mathrm{y}_{\mathrm{i}}=\left(\mathrm{x}_{\mathrm{i}} ; \beta\right) \exp \left(\mathrm{v}_{\mathrm{i}}-\mathrm{u}_{\mathrm{i}}\right), \mathrm{i}=1, \ldots, \mathrm{N} \ldots(1)$ where, $\mathrm{v}_{\mathrm{i}}$ is the random error having zero mean and is associated with random factors that are not under the control of the firm. The model is such that the possible production, $y_{i}$, is bounded above by the stochastic quantity $\left(x_{i} ; \beta\right) \exp \left(v_{i}\right)$, hence the term stochastic frontier (Jondrow et al., 1982; Russel and Young, 1983). The random errors, $v_{i}$ $=1 \ldots \mathrm{N}$ assumed to be independently and identically distributed as $\mathrm{N}\left(0, \sigma_{\mathrm{v}}{ }^{2}\right)$ random variables, independent of $\mathrm{u}_{\mathrm{i}}$ 's, which were assumed to be non-negative truncations of $\mathrm{N}\left(0, \sigma_{\mathrm{u}}{ }^{2}\right)$ distribution (i.e. half normal distribution or having exponential distribution).Through maximum likelihood estimator (MLE) approach, the source of difference between the actual production and the estimated value from the frontier production function was examined by calculating the variance ratio parameter $(\gamma)$. Now, let $\sigma_{u}^{2}$ and $\sigma^{2}$ be the variances of parameters one-sided $(u)$ and symmetric (v). Therefore,

$\sigma^{2}=\sigma_{\mathrm{u}}^{2}+\sigma_{\mathrm{v}}^{2} \ldots(2)$

and the ratio of the two standard errors is

$\lambda=\sigma_{\mathrm{u}} / \sigma_{\mathrm{v}} \ldots \ldots$ (3)

Then the variance ratio parameter $(\gamma)$, which relates the variability of

$\sigma^{2}$ u to the total variability $\sigma^{2}$, is given by Equation (4):

$\gamma=\sigma_{\mathrm{u}}^{2} / \sigma^{2}$

Here, $\gamma$ is defined as the total variation of output from the frontier and can be attributed to technical efficiency. Hence, on the assumption that $u_{i}$ and $v_{i}$ are independent, the variance ratio from frontier $(\gamma)$ has two important characteristics, viz. (i) when $\sigma_{v}$ tends to zero, $u$ is the predominant error in equation (1) and $\gamma$ tends to one. It indicates the differences in technical efficiencies, and (ii) when $\sigma_{\mathrm{u}}$ tends to zero, the symmetric error is the predominant error in equation (1), so it tends to zero. Thus, based on the value of $\gamma$, it was possible to identify whether the difference between output and efficient output was principally due to statistical errors or less efficient use of technology. The $\mathrm{u}_{\mathrm{i}}$ and $\mathrm{v}_{\mathrm{i}}$ parameters of the production frontier equation were estimated using maximum likelihood 
method. Further, given a multiplicative production frontier for which, the Cobb-Douglas production frontier was specified, the technical efficiency of individual mills was estimated by using expectations of $\mathrm{u}_{\mathrm{i}}$, conditional on the random variable $\mathrm{E}_{\mathrm{i}}$ as below:

$\mathrm{TE}_{\mathrm{i}}=\operatorname{Exp}\left(-\mathrm{u}_{\mathrm{i}}\right) ; 0<\mathrm{TE}_{\mathrm{i}}<1 \ldots(5)$

The economic efficiency (EE) is the product of technical efficiency (TE) and allocative efficiency (AE).

In classical economic theory, it is equal to AE itself, as TE is pre-supposed to be one. In the ensuing analysis, various cost components in the sugar industry were converted with prices of each input, to directly estimate EE (Coelli, Rao \& Battese, 2001).

\section{Objectives of the Study}

The present study is an attempt to evaluate efficiency of the selected sugar mills in Bangladesh on the basis of stochastic frontier approach as well as to know the main causes of weak technical efficiency as an aid to develop the situation. The specific objectives of the study are as follows:

1) To know the present status of the sample sugar mills in Bangladesh,

2) To measure the technical efficiency of the selected sugar mills in Bangladesh by investigating into the factors affecting hostile situation,

3) To recommend the ways to overcome the adverse situations and provide suggestions for enhancing the management of the sugar industry in Bangladesh.

\section{Research Methodology}

The study is mainly based on secondary sources like annual reports of sugar mills, reports of the BSFIC, books, articles, theses, etc. Six sugar mills Thakurgaon Sugar Mills Ltd. (TSM), North Bengal Sugar Mills Ltd. (NBSM), Kashtia Sugar Mills Ltd. (KSM), Panchagarh Sugar Mills Ltd. (PNSM) Carew \& Co. (Bangladesh) Ltd. (C \& Co.) and Faridpur Sugar Mills Ltd. (FSM) are selected as sample purposively. The study covers the time periods 2006 to 2015. Collected data are tabulated accordingly in logical order. Data are analyzed using the test of stochastic frontier approach.

\section{Analysis and Finding}

\subsection{Selection of Variables}

The value of total output of sugar to the individual mills has been considered as output variable and the inputs are cost like material (sugarcane) cost, manpower cost, machine cost, energy cost and overhead for the analysis.

\subsection{Cobb-Douglas Production Function}

The analysis has been done through the following three steps procedure:

1) The comparative analysis of OLS estimation of Cobb-Douglas production function of gross production measures of selected sugar mills under study. 
2) Comparative effects of maximum-likelihood estimates for the parameters of the CobbDouglas stochastic frontier production function with the assumption of half-normal for selected sugar mills under review.

3) And maximum- likelihood estimates for the parameters of the time variant inefficiency of Cobb-Douglas stochastic frontier production function with the assumption of truncatednormal for selected sugar mills under review period.

Table 1: OLS Estimation of Cobb-Douglas production function of Value of Production

\begin{tabular}{|l|l|l|l|l|l|l|l|}
\hline \multirow{2}{*}{ Parameters } & \multicolumn{6}{|c|}{ Coefficients of the Parameters of Selected Units. } & \multirow{2}{*}{ Combined } \\
\cline { 2 - 7 } & TSM & NBSM & KSM & PNSM & C \&Co. & FSM & \\
\hline$\beta_{0}$ & 10.43 & 1.54 & -4.45 & 29.64 & -3.58 & -2.97 & $-14.52^{*}$ \\
\hline$\beta_{1}$ (VOP) & 0.95 & $2.75^{*}$ & $3.24^{* *}$ & -0.14 & $4.94^{*}$ & $4.94^{*}$ & $4.91^{*}$ \\
\hline$\beta_{2}$ (M.cost) & 0.46 & $-1.92^{*}$ & -2.33 & 5.09 & $-2.66^{*}$ & $-4.21^{*}$ & $-3.12^{*}$ \\
\hline$\beta_{3}$ (W\& S) & 1.77 & 0.75 & 1.35 & -0.60 & $-1.57^{* *}$ & 0.7 & $2.16^{*}$ \\
\hline$\beta_{4}$ (Mch.C) & $-4.72^{*}$ & $-1.04^{* *}$ & -0.71 & $-9.48^{*}$ & 0.50 & -0.15 & $-1.35^{* *}$ \\
\hline$\beta_{5}$ (E.Cost) & 0.04 & -0.73 & -0.99 & $-5.02^{* *}$ & $-1.55^{*}$ & -1.06 & $-1.27^{*}$ \\
\hline$\beta_{6}(\mathrm{OH})$ & -0.26 & 0.29 & -0.30 & 2.89 & $1.02^{* *}$ & 0.31 & 0.51 \\
\hline$\sigma$ & 0.54 & 0.17 & 0.44 & 1.00 & 0.21 & 0.30 & 0.88 \\
\hline Likelihood & -7.22 & 10.64 & -4.28 & -16.62 & 6.3 & 1.66 & -112.24 \\
\hline Scale & -1.76 & 0.10 & 0.26 & -7.26 & 0.68 & 0.53 & 1.84 \\
\hline
\end{tabular}

$\mathrm{N}=15$ and $* * *$, significance level at $1 \%, 5 \%$ consecutively.

Table \#1 shows comparative analysis of OLS estimation of Cobb-Douglas production function of value added measures of selected sugar mills under study period 2006-2015. The Ordinary least square (OLS) estimates of the parameters of Cobb-Douglas production function shows the average performance of the Sugar mills and estimated parameters are used as initial values (to estimate) for the maximum likelihood estimates of the parameters. The $\sigma$ parameters were positive for all selected units and combined result under study which indicated that the observed output may differ from frontiers which would be within the controls of the management of the selected sugar mills. Furthermore it implied that the average production function using the OLS was not the right estimate of the production function. From the analysis we found that intercept values $\left(\beta_{0}\right)$ of selected units were statistically insignificant but in combined it showed significant impact with negative sign by $(-14.52 *)$. From the table it was observed that the coefficients of total value of production $\left(\beta_{1}\right)$ for all selected units including combined result were statistically significant except TSM (0.95) and PNSM (-0.14) in the production process of value added. The coefficients of total material cost $\left(\beta_{2}\right)$ were found positive and insignificant impact in all the units except TSM (0.46) and PNSM (5.09). The coefficients of wages and salaries $\left(\beta_{3}\right)$ showed negative impact in PNSM $(-0.60)$ and in $C \&$ Co. $(-1.57)$ under the study period. The coefficients of machine cost $\left(\beta_{4}\right)$ showed also negative impact in all the selected units excluding $\mathrm{C} \& \mathrm{Co}$. (0.50) under study period. From the analysis we observed that the coefficients of energy cost $\left(\beta_{5}\right)$ for the all units except TSM $(0.04)$ were negative in sign in the production process of value added. The coefficients of overhead $\left(\beta_{6}\right)$ for all selected units were positive in sign except TSM (-0.26) and KSM (-0.30) in the production process of value added under review period. From the table we observed that the combined results of coefficients of all inputs except overhead cost $\left(\beta_{6}\right)$ were statistically significant. The coefficient of wages and salaries $\left(\beta_{3}\right)$ and coefficients of total value of Production $\left(\beta_{1}\right)$ were significant at 1 percent level by 2.16 and 4.91 respectively in combined results. The 
regression coefficients in the Cobb-Douglas production function elasticity and their sum was found 1.84 indicating increasing return to scale for the combined result of six mills but individually showed decreasing position.

Table 2: Maximum Likelihood Estimation of Cobb-Douglas Production Function of Value Added Measure (Half-Normal with Time-variant inefficiency effect)

\begin{tabular}{|c|c|c|c|c|c|c|c|}
\hline \multirow[t]{2}{*}{ Parameters } & \multicolumn{6}{|c|}{ Coefficients of the Parameters of Selected Units. } & \multirow[t]{2}{*}{ Combined } \\
\hline & TSM & NBSM & KSM & PNSM & C\&Co. & FSM & \\
\hline$\beta_{0}($ Intercept $)$ & 9.75 & -2.76 & -4.46 & $29.60 *$ & -4.50 & -5.58 & -5.13 \\
\hline$\beta_{1}(\mathrm{VOP})$ & 0.86 & $2.75^{*}$ & $3.24 *$ & -0.15 & $4.92 *$ & $5.45^{*}$ & $4.63 *$ \\
\hline$\beta_{2}(\mathrm{TMC})$ & 0.45 & $-2.06 *$ & $-2.32 * *$ & $5.08 *$ & $-2.83 *$ & $-3.95 *$ & $3.05 *$ \\
\hline$\beta_{3}(\mathrm{~W} \& S)$ & 1.85 & $0.98 *$ & $1.35 * *$ & 0.61 & -1.28 & 0.80 & 1.21 \\
\hline$\beta_{4}$ (M.Costs) & $-4.79 *$ & -0.33 & -0.07 & $-9.49 *$ & 0.43 & -0.35 & $-2.50 *$ \\
\hline$\beta_{5}($ E.Costs $)$ & 0.15 & $-1.16^{*}$ & $-0.99 * *$ & $-5.02 *$ & $-1.29 * *$ & $-1.74 *$ & -0.78 \\
\hline$\beta_{6}(\mathrm{OH})$ & -0.20 & $0.63 *$ & -0.30 & $2.89 *$ & $0.95 * *$ & 0.36 & $1.08 * *$ \\
\hline$\sigma^{2}$ & 0.19 & 1.03 & $0.10 * *$ & 0.57 & 0.07 & 0.04 & $1.92 * *$ \\
\hline$\gamma$ & 0.21 & $0.99 *$ & 0.00 & 0.00 & 0.67 & 0.18 & $0.74 *$ \\
\hline$\mu$ & 0.00 & 0.00 & 0.00 & 0.00 & 0.00 & 0.00 & 0.00 \\
\hline$\eta$ & -0.32 & -0.09 & -0.04 & -0.01 & -0.28 & 1.65 & -0.04 \\
\hline $\mathrm{U}=\sigma_{\mathrm{u}}{ }^{2}$ & 0.04 & 1.03 & 0.00 & 0.00 & 0.05 & 0.01 & 1.42 \\
\hline $\mathrm{V}=\sigma_{\mathrm{V}}^{2}$ & 0.15 & 0.00 & 0.10 & 0.57 & 0.02 & 0.03 & 0.50 \\
\hline$\lambda=\left(\sigma_{\mathrm{u}}^{2} / \sigma_{\mathrm{v}}^{2}\right)^{1 / 2}$ & 0.52 & 15.78 & 0.00 & 0.00 & 1.42 & 0.47 & 1.69 \\
\hline Likelihood & -7.10 & 16.95 & -4.28 & -16.63 & 6.71 & 3.43 & -104.13 \\
\hline Mean(eff.) & 36.26 & 89.16 & 74.05 & 22.63 & 70.34 & 34.28 & 54.45 \\
\hline
\end{tabular}

$\mathrm{N}=15$ and $*, * *$, significance level at $1 \%, 5 \%$ consecutively.

Table \#2 represents the comparative results of maximum-likelihood estimates for the parameters of the time variant inefficiency Cobb-Douglas stochastic frontier production function with the assumption of half-normal for selected sugar mills under review period 2006-2015. It was evident from the table that in case of the coefficients of total value of production $\left(\beta_{1}\right)$ for all selected units excluding TSM (0.86) and PNSM (-0.15) were positive significant impact in the value added creation process. The coefficient of total material cost $\left(\beta_{2}\right)$ had positive significant impact on PNSM (5.08) and combined result (3.05) in the review period. The coefficient of wages and salaries $\left(\beta_{3}\right)$ showed negative sign in $C \& C o$. under the review period. The coefficients of machine cost $\left(\beta_{4}\right)$ were negative in sign with statistically significant for all of the units excluding C\& Co. From the analysis we observed that the coefficients of energy cost $\left(\beta_{5}\right)$ for all units except TSM showed negative impact in the production process of value added. The coefficients of overhead $\left(\beta_{6}\right)$ were found positive statistically significant impact in NBSM, PNSM, C\& Co and combined results in the production process of value added. It was found that significant coefficients of $\sigma^{2}$ were in KSM and combined result by 0.10 and 1.92 respectively. $\lambda$ (Lambda), the ratio of $\sigma_{u}$ over $\sigma_{\mathrm{v}}$ was found greater than unity in NBSM, C \&Co. and Combined by 15.78, 1.42 and 1.69 respectively. For this distribution $\gamma$ (Gama) was enumerated highest (99\%) for NBSM and lowest $(0 \%)$ for KSM and PNSM. The estimation of the parameters $\eta($ eta) was found negative sign in all selected units except FSM indicated increase of inefficiency except FSM where efficiency was increasing over the time period. It was revealed that the technical efficiency of the selected units 
during the period 2006-2014 for half-normal assumption was estimated highest at 89.16 percent at NBSM and lowest at 22.63 percent at PNSM with combined at 54.45 percent. This value also indicated that the management of the said mills could improve its output level of value added by 10.84 percent and 77.37 percent respectively with combined 45.55 percent by the same sets of inputs used in the creation procedure of value added.

Table 3: Maximum Likelihood Estimation of Cobb-Douglas Production Function of Value Added Measures (Truncated-Normal with Time-Variant Inefficiency Effect)

\begin{tabular}{|l|l|l|l|l|l|l|l|}
\hline \multirow{2}{*}{ Parameters } & \multicolumn{3}{|l|}{ Coefficients of the Parameters of Selected Units. } & \multirow{2}{*}{ Combined } \\
\cline { 2 - 7 } & TSM & NBSM & KSM & PNSM & C \&Co. & FSM & \\
\hline$\beta_{0}$ & $10.10^{*}$ & 1.56 & $-4.40^{*}$ & $29.60^{*}$ & $-3.55^{*}$ & $-2.94^{*}$ & -3.09 \\
\hline$\beta_{1}$ & 0.88 & $2.73^{*}$ & $3.23^{*}$ & -0.17 & $4.93^{*}$ & $5.01^{*}$ & $4.39^{*}$ \\
\hline$\beta_{2}$ & 0.43 & $-1.92^{*}$ & -2.32 & $5.10^{*}$ & $-2.66^{*}$ & $-4.19^{*}$ & $-2.82^{*}$ \\
\hline$\beta_{3}$ & $1.73^{*}$ & 0.74 & $1.34^{* *}$ & -0.60 & -1.58 & 0.65 & $1.48^{* *}$ \\
\hline$\beta_{4}$ & $-4.69^{*}$ & -1.03 & -0.07 & $-9.49^{*}$ & 0.51 & -0.20 & $-3.04^{*}$ \\
\hline$\beta_{5}$ & 0.13 & -0.73 & $-0.98^{* *}$ & $-5.03^{*}$ & -1.53 & -1.13 & -0.66 \\
\hline$\beta_{6}$ & -0.20 & 0.32 & -0.30 & $2.90^{*}$ & 1.02 & 0.35 & $0.94^{*}$ \\
\hline$\sigma^{2}$ & $0.15^{*}$ & $0.02^{* *}$ & $0.10^{* *}$ & 0.53 & 0.03 & 0.05 & $1.10^{*}$ \\
\hline$\gamma$ & 0.04 & 0.11 & 0.00 & 0.00 & 0.02 & 0.11 & $0.55^{* *}$ \\
\hline$\mu$ & 0.15 & 0.08 & -0.01 & 0.02 & 0.05 & -0.150 & 1.25 \\
\hline$\eta$ & -0.19 & -0.20 & -0.03 & 0.03 & -0.14 & 0.18 & -0.01 \\
\hline$U=\sigma_{\mathrm{u}}^{2}$ & 0.01 & 0.00 & 0.00 & 0.00 & 0.00 & 0.01 & 0.61 \\
\hline $\mathrm{V}=\sigma_{\mathrm{v}}{ }^{2}$ & 0.14 & 0.01 & 0.10 & 0.53 & 0.03 & 0.04 & 0.50 \\
\hline$\lambda=\left(\sigma_{\mathrm{u}}{ }^{2} / \sigma_{\mathrm{v}}{ }^{2}\right)^{1 / 2}$ & 0.21 & 0.35 & 0.01 & 0.01 & 0.14 & 0.35 & 1.11 \\
\hline Likelihood & -7.08 & 11.22 & -4.28 & -16.61 & 6.50 & 1.97 & -103.90 \\
\hline Mean(eff. $)$ & 22.07 & 79.22 & 42.20 & 12.46 & 39.56 & 17.20 & 35.45 \\
\hline
\end{tabular}

$\mathrm{N}=15$ and $* * *$, significance level at $1 \%, 5 \%$ consecutively.

Table \# 3 represents the measures of the Comparative results of maximum-likelihood estimates for the parameters of the time variant inefficiency Cobb-Douglas stochastic frontier production function with the assumption of truncated-normal for selected sugar mills under review period 1996-2010. It was evident from the table that in case of the coefficients of total value of production $\left(\beta_{1}\right)$ for all selected units excluding TSM (0.88) and PNSM (-0.17) were positive significant impact in the value added creation process. The coefficient of total material cost $\left(\beta_{2}\right)$ had positive significant impact on PNSM (5.10), positive impact on TSM (0.43) and rest units showed negative significant impact under the review period. The coefficient of wages and salaries $\left(\beta_{3}\right)$ showed negative sign in PNSM and C\& Co. whereas it showed positive significant impact on TSM, KSM and on combined result under the study period. The coefficients of machine cost $\left(\beta_{4}\right)$ were negative in sign for all of the units excluding C\& Co. From the analysis we observed that the coefficients of energy cost $\left(\beta_{5}\right)$ for all units except TSM showed negative impact in the production process of value added. The coefficients of overhead $\left(\beta_{6}\right)$ were found positive statistically significant impact in PNSM, and combined results in the production process of value added. It was found that significant coefficients of $\sigma^{2}$ were found in TSM, NBSM and combined results. $\lambda$ (Lambda), the ratio of $\sigma_{\mathrm{u}}$ over $\sigma_{\mathrm{v}}$ was found greater than unity in combined impact. For this distribution $\gamma$ was enumerated $(55 \%)$ for combined impact whereas the highest (11\%) both for NBSM and FSM, 
lowest $(0 \%)$ for KSM and PNSM. The estimation of the parameters $\eta(e t a)$ were found highest (0.18) for TSM and lowest (-0.20) for NBSM. The negative sign of this parameter indicated that the technical inefficiency tends to increase over time. It was revealed that the technical efficiency of the selected units during the period 2006-2015 for truncated-normal assumption was estimated highest at 79.22 percent at NBSM and lowest at 12.46 percent at PNSM with combined at 35.45 percent. This value also indicated that the management of the said mills could improve its output level by 20.78 percent and 87.54 percent respectively with combined64.55 percent by the same sets of inputs used in the procedure of value added creation.

\section{Conclusion}

The $\sigma$ parameter was found with positive values indicating potential production deferred from actual production. The return to scale of the sample was estimated 1.84 implied increasing returns to scale. The parameter $\left(\beta_{0}\right)$ of OLS for the sample was found less than that of MLE for the cause of below position of potential output. $\lambda$ (Lambda) was the ratio of variance of industry specific production behaviors $\sigma^{2}(\mathrm{u})$ to the variance of statistical noise $\sigma^{2}(\mathrm{v})$. Here that ratio was for found 1.69 and 1.11 for the half-normal and truncated normal distribution which indicated that there were impacts due to inefficiency of the management dominated by random disturbances of sugar industry. The value of $\gamma$ was estimated 74 percent and 55 percent for half normal and truncated normal indicating 74 percent and 55 percent output in sugar production were due to inefficiency of the management. The parameter $(\eta)$ was found negative for both the methods which indicated that the technical efficiency was decreasing over the time. The mean technical efficiency of sample was 54.45 percent and 35.45 percent for the half normal and truncated normal distribution. This further indicated that the management could increase the production level by 45.55 percent and 64.55 percent respectively using same level of inputs. From the sensitivity analysis it was estimated value of production was the most sensitive input among the input variable under study.

\section{Suggestions and Recommendations}

The factors that improve overall efficiency of sugar mills in Bangladesh:

1) To introduce high yield variety of sugarcane this contained sufficient sucrose content.

2) To ensure proper utilization of money, machine and materials.

3) To develop managerial skill that should be improved the managerial efficiency.

4) To increase skilled manpower that should be enhanced higher level of production.

5) To ensure cordial relationship among management, growers, workers, employers.

6) To introduce required BMRE activities duly by the concern authority.

7) To ensure proper training for the existing manpower.

8) To take necessary actions of reduction of inventory.

\section{References}

[1] Economic Adviser's Wing, Finance Division, Ministry of Finance, Government of the People's Republic of Bangladesh. (2010). Bangladesh Economic Review . Dhaka: Bangladesh Government Press, Tejgaon, Dhaka-1208. 
[2] Asante, J. A., \& Sekyi, S. (May 2016). Stochastic Frontier Analysis of Production Technology: An Application to the Pharmaceutical Manufacturing firms in Ghana. World Journal of Current Economics Research, Vol 2, No.1, pp.1-20.

[3] Bangladesh Sugar and Food Industries Corporation. (2009). Annual Performance Report of Bangladesh Sugar and Food Industries Corporation. Dhaka: MIS \& ICT Departmen, Chinishilpa Bhaban (7th floor), 3, Dilkusa Commertial Area, Dhaka-100.

[4] Bhat, R., Verma, B. B., \& Reuben, E. (2001). Hospital Efficiency and Data Envelopment Analysis (DEA): An empirical analysis of district hospitals and grant-in-aid hospitals in Gujarat state of India . Ahmedabad: Indian Institute of Management.

[5] Coelli, T. J. (1996). A Guide to FRONTIER Version 4.1: A Computer Program for Stochastic Frontier Estimation, CEPA working paper 96/07. Australia: Department of Economics, University of New England Armidale.

[6] Coelli, T. J., Rao, D. P., \& Battese, G. E. (2001). An Introduction To Efficiency and Productivity Analysis. Boston/ Dordrecht/ london: Kluwer Academic Publishers.

[7] Habib, M. A., \& Ljungqvist, A. ( Appril 21, 2003, Appril). Firm Value and Managerial Incentives: A Stochastic Frontier Approach. Switzerland: National Centre of Competence in Research Financial Valuation and Risk Management.

[8] Mahmud, T., Ghani, E., \& Uddin, M. (206). Efficiency of Large-scale Manufacturing in Pakistan: A Production Frontier Approach. The Pakistan Development Review, 45: 4 Part- II, 689-700.

[9] Muellabuer, J. (1991). Productivity and Competitiveness. Oxford Review of of Economic Policy, (7), 99-117.

[10] Prabowo, T. E., \& Cabanda, E. ( 2011). Stochastic Frontier Analysis of Indonasian Firm Efficiency: A Note. International Journal of Banking and Finance, Volume 8 (Number 2), pages 74-91.

[11] Rahman, K. M., Mia, M. I., \& Bhuiyan, M. K. (2012). A Stochastic Frontier Approach to Model Technical Efficiency of Rice Farmers in Bangladesh:An Empirical Analysis. A Scientific Journal of Krishi Foundation, 9-19.

[12] Sinani , E., JOnes, D. C., \& Mygind, N. (2005). Determinants of Firm Level Technical Efficiency: A Stochastic Frontier Approach. European International Business Association Annual Conference (pp. 50-62). Hamilton: Copenhagen Business School, Porcelaenhaven24, 2000 Frederiksbarg.

*Corresponding author.

E-mail address: drabusina1970@ gmail.com 